This is a self-archived version of an original article. This version may differ from the original in pagination and typographic details.

Author(s): Siponen, Mikko; Tsohou, Aggeliki

Title: Demystifying the Influential IS Legends of Positivism

Year: 2018

Version: Published version

Copyright: (c) the Authors \& Association for Information Systems, 2018.

Rights: In Copyright

Rights url: http://rightsstatements.org/page/InC/1.0/?language=en

Please cite the original version:

Siponen, M., \& Tsohou, A. (2018). Demystifying the Influential IS Legends of Positivism. Journal of the Association for Information Systems, 19(7), 600-617.

https://doi.org/10.17705/1jais.00503 


\title{
Demystifying the Influential IS Legends of Positivism
}

\author{
Mikko Siponen', Aggeliki Tsohou ${ }^{2}$ \\ ${ }^{1}$ University of Jyväskylä, Faculty of Information Technology, Finland, mikko.t.siponen@jyu.fi \\ ${ }^{2}$ Department of Informatics, Ionian University, Greece, atsohou@ionio.gr
}

Abstract

\begin{abstract}
Positivism has been used to establish a standard that Information Systems (IS) research must meet to be scientific. According to such positivistic beliefs in IS, scientific research should: 1) be generalizable, 2) focus on stable independent variables, 3) have certain ontological assumptions, and 4) use statistical or quantitative methods rather than qualitative methods. We argue that logical positivist philosophers required none of these. On the contrary, logical positivist philosophers regarded philosophizing in general and ontological considerations in particular as nonsense. Moreover, the positivists' preferred empirical research method was not a survey, but rather a qualitative observation recorded by field notes. In addition, positivist philosophers required neither statistical nor nonstatistical generalizability. At least some positivist philosophers also acknowledged the study of singular cases as being scientific. Many research orientations (e.g., single-setting research, examination of change, qualitative research) that are deemed "unscientific" by positivism in IS seem to be "scientific" (in principle) according to logical positivism. In turn, generally speaking, what has been justified as scientific by positivism in IS (e.g., requirements of statistical or nonstatistical generalizability, surveys, independent variables, ontological views) were either not required by logical positivists or were regarded as nonsensical by logical positivists. Furthermore, given that positivism is sometimes associated (or confused) with logical empiricism in IS, we also briefly discuss logical empiricism. Finally, realizing that certain influential, taken-forgranted assumptions that underlie IS research are unwarranted could have ground-breaking implications for future IS research.
\end{abstract}

Keywords: Positivism, Logical Empiricism, Logical Positivism, Philosophy of Science, IS Philosophy

Shirley Gregor was the accepting senior editor. This research article was submitted on May 6, 2016 and went through 2 revisions

\section{Introduction}

Logical positivism (LP), also known as positivism, is a well-known philosophical movement (Laudan, 1996). Arguably, the beliefs of positivism have influenced the information systems (IS) field more than any other philosophical "ism". For example, in the year (2004), 27\% of the MISQ articles justified their fundamental research assumptions either as in line with, or against, positivism. In the field of IS, positivism has been utilized to authorize common research assumptions - e.g., generalizability, survey research, and identifying stable independent variables (Orlikowski \& Baroudi, 1991; Lee \& Baskerville, 2003). In IS, positivism has also been used to discern what constitutes scientific and unscientific research (Klein \& Myers, 1999). For example, Lee and Hubona (2009) claimed that "positivism requires the social sciences to incorporate these elements [independent and dependent variables, quantitative data, inferential 
statistics] if they are to become as scientific as natural sciences" (p. 237). We assert that LP did not require any of these elements in order for a study to be regarded as scientific.

Given that positivism is often used to establish a standard for scientific research in IS, it is critical to determine to what extent IS beliefs regarding positivism are actually supported by the philosophers who constituted logical positivism. We performed this task by first analyzing articles from six journals between 2002-2015 that justified their research as being in support of positivism, or against it. This resulted in a total of 278 articles. Our review of these articles showed that IS beliefs about positivism were shaped by several influential papers describing positivism. Unfortunately, these few influential sources of positivism are mainly based on misreading literature that describes LP. Perhaps due to such misunderstandings, the standard that logical positivist philosophers set for scientific research and philosophy is (generally speaking) very different than that presented by many IS articles. For example, what has been often regarded as unscientific in IS per LP (e.g., single-setting studies and qualitative observations), seems to be (in principle) acceptable to logical positivists. In turn, many assumptions in IS that have been justified as scientific according to the authority of positivism (e.g., discussion of ontological assumptions) either were not required by logical positivists, or were regarded as nonsense by logical positivists.

Since positivism in IS research is sometimes conflated with logical empiricism (LE), we also briefly discuss LE, which can be seen as the "successor" of LP.

Our findings challenge many influential and regulative IS beliefs about positivism. We urge future researchers studying IS philosophy to start reexamining the fundamental assumptions of IS research, including beliefs that have been assumed to be based on logical positivism, logical empiricism, or those that have been taken for granted.

\section{Positivism: A Very Short Story}

While August Comte first introduced the term "positivism" (Bourdeau, 2013), in the philosophy of science during the nineteenth century, positivism

\footnotetext{
${ }^{1}$ Carnap, Neurath and Schlick seem to assume that scientists did not waste their time in metaphysical discussions. Carnap also believed that philosophy could learn from mathematics: "In contrast to the endless controversies among the various schools of philosophy, the results in mathematics could be proven exactly and there was no further controversy." (Carnap, 1963a, p. 4).

${ }^{2}$ For example, "most of the propositions and questions to be found in philosophical works are not false but nonsensical" (Wittgenstein, 1922, p. 4.003).
}

commonly refers to the logical positivism movement (LP) originating in the early twentieth century. (Carnap, 1936; Laudan, 1968; 1996). Three figures were especially influential in the formation of the theses of LP: Moritz Schlick (founder of LP), Rudolf Carnap (first joined as Schlick's assistant), and Otto Neurath (cofounder of LP) (Hempel, 1935; Uebel, 2014); the highly influential theses of positivism would not have been formulated without these key figures (Manninen, 2002). These philosophers, and others, known collectively as the "Vienna Circle," developed their ideas in weekly LP discussions occurring primarily during the 1920s and 30s in Vienna.

\subsection{Speculative Philosophy is Nonsense, and Philosophy Must Learn from Science}

Logical positivists felt that many philosophical problems, especially regarding metaphysics (including ontology, i.e., existence and reality), are nonsense, a major source of philosophical confusion and therefore waste of time. For example, Carnap asked, "Can it be that so many men, of various times and nations, outstanding minds among them, have devoted so much effort, and indeed fervor, to metaphysics, when this consists of nothing more than words strung together without sense?" (Carnap, 1932a). Logical positivists wanted to stop empty philosophizing and suggested that philosophy should instead learn from the success of the sciences. ${ }^{1}$

Logical positivist Schlick found that Wittgenstein's (1921) Tractatus Logico-Philosophicus offered a viable way to achieve this. ${ }^{2}$ The debate, influenced by Wittgenstein's (1921) Tractatus in the logical positivists' intense meetings, resulted in the most wellknown theses of LP, namely: (1) analytic/synthetic knowledge, and (2) a verifiable criterion of meaning (Schlick, 1932). 3 Even though textbook presentations of LP may regard these as the common theses of LP, Carnap, Neurath, and Schlick actually often had different views on the philosophy of science. Similar to textbook presentations of LP, this paper portrays the logical positivists' views more coherently than they actually were.

\footnotetext{
3 While the LP members had different influences, the analytic/synthetic thesis was influenced by Frege, Russell, Wittgenstein, and Gödel (Carnap, 1963a; Creath, 2017). The LP analytic/synthetic thesis viewed logic and mathematics as analytic, a priori, decided formally by following logical and mathematical rules. In turn, empirical claims were synthetic and had to be tested empirically in a certain manner, proposed by the verifiable criterion of meaning. Any other type of knowledge claim was rejected as meaningless metaphysics.
} 


\subsection{What are Metaphysics, Analytical/Synthetic, and the Verification Principle?}

Logical positivists (Carnap, Neurath, and Schlick) regarded metaphysical (e.g., ontological) considerations as the primary source of confusion and nonsense in philosophy. To remove such nonsense from philosophy, the logical positivists' tactic sought to render metaphysical claims meaningless (Holton, 1993). How then do we recognize this meaningless metaphysics? What precisely constitutes metaphysics and meaninglessness? To describe the complex LP ideas to nonphilosophers, we simplify the ideas of LP as follows:

1. Logical positivists did not require a new theory or new theoretical contributions.

2. If a scientific claim (or "theory") has a number of claims (hypotheses, propositions), each claim must be evaluated individually, one by one.

3. Meaningful claims are either analytic or synthetic.

4. Analytic claims can be (dis)proven by mathematics/logic.

5. Synthetic claims can be shown to be true/untrue by using the verification thesis.

6. Any terms/concepts that are not analytic or synthetic are meaningless, and should be removed from the claims.

The logical positivists thus did not evaluate a set of claims (or a "theory" consisting of a set of claims) as a whole, but on a statement-by-statement basis, in order to determine whether each statement was meaningful or not. For LP, meaningful statements are either analytic or synthetic. Roughly speaking, the former means proven mathematically/logically, while the latter means tested empirically with observable and identifiable characteristics. How did the logical positivists separate the meaningful from the meaningless? Roughly speaking, the basic idea was to select a claim (hypothesis, proposition) and ask what the claim was fundamentally about. More specifically, does the sentence concern a mathematical or logical riddle (i.e., analytic)? If yes, then it should be provable by mathematics or logic. For LP, analytical statements could be validated independently of empirical experience (observations), i.e., on formal grounds (Uebel, 2014). If the claim is empirical, and the question is empirical in nature (i.e., synthetic), then it must be verifiable empirically. If that verification fails,

\footnotetext{
${ }^{4}$ The verification idea was advocated especially by Schlick and it was influenced by Wittgenstein's Tractatus. We also suggest the interpretation that Schlick advocated verification, because he believed that the verification by observation (see e.g., Schlick, 1932) is a key scientific method. Neurath did not accept the verification thesis (Manninen, 2002). For
}

then the scientific sentence is untrue. ${ }^{4}$ If the sentence is not empirical or mathematical (logical), then it is metaphysical, and the metaphysics should be eliminated from the sentence.

What counts as verified? The version of the verification thesis that is known as LP's verification criterion had an absolute requirement for verification (empirical test). A direct sensory experienceobservation-was required (later, an indirect experience was also accepted) (Uebel, 2013). Verification can be described by using observation characteristics and an observation sentence (Hempel, 1950, p. 42). For example, "this apple is red" is an observation sentence in which the apple is the object and red is the observable characteristic (Hempel, 1950). This sentence meets the requirement because the object and its color can be verified by direct observation (Hempel, 1950).

\subsection{LP and Its Alleged Demise}

Although the aim of LP was to have an absolute criterion that rendered successful science meaningful and metaphysics meaningless (unscientific), this proved quite difficult to achieve. Thomas Kuhn (1962), Willard Van Orman Quine (1951), and Paul Feyerabend (1975) showed that scientific theories, or even a single synthetic statement, necessarily included assumptions that were meaningless (metaphysical) according to LP (see Section 4.6: Objective Data and LP). Moreover, one could ask whether the principle of verification itself meets the verification or analytical/synthetic criterion. Indeed, verification is not analytic, but rather seems synthetic. Can we then create a test that shows that verification is the correct method? We can hardly even design such a test with an observable effect. Should we then regard verification as metaphysical and meaningless in the light of LP theses?

Owing to these (and many other) problems, it was reported by Karl Popper (1934) and John Passmore (1967) that LP had been "killed." The demise of LP has been attributed to influential criticisms of logical positivism, including those by Popper (1934), Quine (1951), Kuhn (1962), Feyerabend (1975), Norwood Russell Hanson (1958), and Wittgenstein (1958). ${ }^{5}$ However, before any of these works were published, the key members of LP had already abandoned the verification method as well as the ambition to establish an absolute criterion to separate "meaningful" from "meaningless," and had also dispensed with any labels

differences between Schlick and Neurath, see Hempel (1935).

${ }^{5}$ Also, Reichenbach's critique of LP's absolute verification requirement appeared in 1931 and later in 1938. Wittgenstein's later thinking (1929 onward) can also be viewed as a critique of LP (Laudan, 1996; Stern, 2007). 
identifying them with positivism or LP (Carnap, 1942; Salmon, 2005). These famous LP theses 6 "died" primarily not due to Quine (1951), Hanson (1958), Kuhn (1962), or Popper (1934), but because the LP members themselves no longer believed in their absolute ideas, and abandoned them accordingly. However, Neurath's LP views did survive critiques by Quine and Hanson (Cat, 2014; Manninen, 2002). ${ }^{7}$

\subsection{What Happened After LP? LP Philosophers Quit Positivism and Started Logical Empiricism}

This section discusses what happened after LP members rejected the basic tenets of LP. While the precise time that LP members rejected LP is debatable, Salmon (2005) noted that by 1935, all key members of the movement had "abandoned the designation of 'logical positivism.' After that, logical positivism no longer existed" (p. 19). Internal critiques (especially by Neurath) spurred logical positivists to omit even the name "positivist" or "logical positivist," and they started to use different developed doctrines they called "logical empiricism" (LE). This may explain why LP, the Vienna Circle, and the positivist approach are associated with logical empiricism in IS ${ }^{8}$ (e.g., Evaristo \& Karahanna, 1997; Lee, 1991). Such confusion between LP and LE may also explain why Carl Hempel and his deductive-nomological model have been regarded as positivist in IS (Evaristo \& Karahanna, 1997; Lee, Briggs, \& Dennis, 2014). To our understanding, Hempel, however, was a logical empiricist who did not play an important role in the development of LP theses. ${ }^{9}$ Nevertheless, given that LE is different from LP, exactly what is LE?

There are many LE philosophers who disagreed on most, if not all, specific issues (Creath, 2017). We now turn to a brief description of the basic ideas that are attributed to LE, and introduce the foundational LE philosophers by dividing them into the following four groups (Creath, 2017):

6 E.g., analytic/synthetic, verification, separating meaningless and meaningful, regarding metaphysical questions as meaningless pseudoproblems.

${ }^{7}$ Quine's (1951) critique of analytic/synthetic (first dogma) does not apply to Neurath's LP. Quine's critique (second dogma) of verification and the concern of theory-free observation applies less to Neurath (Uebel, 1997). Neurath noted how observations are theory-laden.

${ }^{8}$ A. J. Ayer's (1936) writing on the Vienna Circle is also a potential source of confusion between LP and LE. Ayer admitted in 1979 that "the most important of the defects [in logical positivism] was that nearly all of it was false." (Hanfling, 1996, p. 5).

${ }^{9}$ Hempel's own work regarding LP has been a critique of LP (e.g., Hempel, 1950) or an explanation of Schlick and
1. Ex-logical positivists (e.g., Carnap, Neurath) who began to refer to themselves as logical empiricists.

2. The Berlin Group, led by Hans Reichenbach.

3. Philosophers (e.g., Feigl, Gödel, Kaila, Nagel, Popper, Quine, Ramsey, and Tarski) who were at some point influenced by LP.

4. Philosophers who were inspired or educated by the Berlin Group (e.g., Dubislav, Hempel, Lewin, von Mises, and Oppenheim).

This classification (by Creath, 2017) constitutes a textbook simplification and identifies individuals who participated in LE themes at some point. For example, Popper classified himself as a "critical rationalist." Eino Kaila utilized the term logical empiricism in 1926 to separate himself from logical positivism (von Wright qtd. in Uebel, 2013). Neurath also used the term logical empiricism (Neurath qtd. in Milkov, 2013), and Reichenbach formally introduced the term "logical empiricism" (Reichenbach, 1936). Reichenbach was a key figure in Berlin's discussion group, referred to as "Berlin logical empiricism" (1936). ${ }^{10}$

Milkov (2013) and Salmon (2001) claimed that a key movement from LP to LE focused on the logical analysis of the sciences, although this means different things for different LE philosophers ${ }^{11}$ (Milkov, 2013; Salmon, 2001). By 1920, Reichenbach had already introduced the method of the "logical analysis of science" (Reichenbach, 1920, p. 74). His Berlin logical empiricism group was closely aligned with the natural sciences and was in constant contact with scientists and mathematicians - the most notable being Einstein and Hilbert, respectively (Milkov, 2013). The Berlin group analyzed the newest scientific discoveries and discussed what philosophy could learn from these (Milkov, 2013). Moreover, Reichenbach (1951) believed that logical analysis, especially the axiomatization of different scientific theories, would help scientists to correct their theories, as scientists do not have time to make their theories logical or coherent. ${ }^{12}$ Some LP members regarded such axiomatizations as metaphysical (Milkov, 2013).

Neurath (Hempel, 1935). Hempel's students named him as a logical empiricist who is "perhaps the most astute critic of" LP (Fetzer, 2014).

${ }^{10}$ From 1929 to 1933, until Reichenbach's professorship was terminated - because he was accused of being half-Jewishand he moved to Istanbul (Siitonen, 2002).

11 For example, even Reichenbach and Carnap viewed logical analysis differently (e.g., Reichenbach, 1936; Milkov, 2013).

12 "Scientific research does not leave a man [a scientist] time enough to do the work of logical analysis, and that conversely logical analysis demands a concentration which does not leave time for scientific work-a concentration which because of its aiming at clarification rather than discovery may even impede scientific productivity." 


\subsection{LE and Some of its Key Problems}

Numerous philosophers associated with LE continued their methods of logical analysis, but omitted the close contact with natural sciences that many of the LE founders advocated. One explanation for this is the professionalization of philosophy. Philosophy departments, which educated philosophers who did not have expertise in performing research, were widely established. Philosophy began to drift apart from the natural sciences, which raised concerns. A common concern was what McMullin (1970, p. 14) referred to as the "danger of logical escapism." Specifically, it was asserted that the formal system-building and logical analysis had "become an end itself" (McMullin, 1970 p. 14) and resulted in "exercises in logic" that do not serve the understanding of how successful scientists or science operate. Laudan claimed that the most prestigious philosophy of science journals ${ }^{13}$ in the 1960s were dominated by logical empiricist articles that lacked "any hint of real science-whether historical or contemporary." (Laudan, 1989, p. 10). Former LP member Herbert Feigl, who advocated the move from LP to LE (Feigl, 1963), criticized LE philosophers for referring to natural scientists (e.g., Newton and Einstein) inaccurately to suit their needs and bemoaned that they lacked a genuine interest in examining the scientists' cases that they referred to in detail, which Feigl found constituted "inexcusable conduct" (Feigl, 1970, p. 3). Feigl (1970) confessed that he also had engaged in this sin earlier in his career. In addition, the widely cited "axiomatic philosopher" Hempel admitted later in his career that the axiomatization of science was less fruitful than he had previously believed (Hempel qtd. in Nolan, 2000, p. 11). Feyerabend (1970, p. 172) claimed that the philosophy of science was closer to actual science during the time of the scientific revolution (the sixteenth and seventeenth centuries); whereas, since the advent of LE, much of the philosophy of science increasingly focused on building "beautiful but useless formal castles" (Feyerabend, 1970, p. 183). ${ }^{14}$

Those philosophers who engaged in the natural scientific case studies and proposed philosophical theories based on them are sometimes referred to as the "historical school" or "theorists of scientific change," and include Buchdahl, Cohen, Hanson, Stegmuller, Hesse, Kuhn, Lakatos, McMullin, Toulmin,

(Reichenbach, 1951, p. 123). Such logical analysis was the task of professional philosophers of science (ibid, p. 123).

${ }^{13}$ Laudan mentions Philosophy of Science and The British Journal for the Philosophy of Science.

${ }^{14}$ This could characterize much of the logical empiricism around 1940-1970. However, contemporary philosophy of science includes many philosophers whose philosophizing is based on actual cases of natural or social sciences.

${ }^{15}$ In addition to "historical school" or "theorists of scientific change," naturalism emphasizes the role of (natural) sciences
Feyerabend, Laudan, Shapere, and Sneed (Laudan, 1989, p. 11; Laudan et al., 1986). ${ }^{15}$ For these individuals, many key issues in the philosophy of science are not ultimately logical enigmas, but rather concern the historical-empirical scrutiny of actual scientific practice. This does not mean that conceptual analysis is not required. Instead, a philosophy explaining the success of the natural sciences must be able to show that its tenets match the actual science (Laudan et al., 1986). However, this group of philosophers disagreed on a number of specific issues, including whether it is sufficient to read science directly in publications, or whether the actual science behind these publications should be examined (Giere, 1973; McMullin, 1970; Burian, 1977).

Formal escapism in LE has also inspired criticism by those philosophers who did not necessarily associate themselves with the historical school, but nevertheless also saw a close connection between philosophy and the natural sciences. For example, shortcomings of the Hempel-Oppenheim deductive-nomological model of explanations (Hempel \& Oppenheim, 1948) have motivated philosophers to develop different mechanism-based explanations by examining different natural sciences (e.g., Bechtel \& Abrahamsen 2005; Machamer, Darden, \& Craver, 2000) and social sciences (e.g., Hedström \& Ylikoski, 2010). Functionbased explanations can also be added to this list (Godfrey-Smith,1993, 1994).

Textbooks sometimes report LE as being "dead." Many philosophers have put forward similar reports: "There are today only a few philosophers of science who would defend any major logical empiricist doctrines in anything like their original form" (Giere, 1988 , p. 28). Our opinion is that philosophical findings derived from specific scientific disciplines (e.g., biology, biochemistry, and medical research) have rendered questionable those LE doctrines that present universal views of science. Again, a classic example is the Hempel-Oppenheim model. The realization that individual sciences are different has led the philosophy of science to focus on increasingly specialized philosophies of sciences-e.g., the philosophy of social sciences, the philosophy of economics, the philosophy of physics, the philosophy of medicine, and the philosophy of biology. It is also important to note that the relevance of LE accounts, such as the Hempel-

in the philosophy of science. For example, Giere (1988), a naturalist philosopher, suggested that sciences do not need a distinctive philosophical foundation: "The people best equipped to engage in such pursuits are not those trained as philosophers, but those totally immersed in the scientific subject matter-namely scientists" (p. xvi). As with philosophical "-isms" in general, naturalism is not a homogeneous movement. 
Oppenheim model, have been seriously contested even in physics (Cartwright, 1983; Giere, 1988; Wayne, 2011). Despite the critique, it is not too difficult to find contemporary philosophers who refer to "science" without presenting concrete scientific cases to justify their theses (in terms of scientific realism, for example, see Laudan, 1981). However, such philosophers may not refer to themselves as logical empiricists. On the other hand, there seem to be lines of LE research themes that are still active. Examples of this include Carnap's probability views, which also involved cooperation with John Kemeny, who codeveloped the BASIC programming language in the 1960s. Perhaps an even more influential example in the philosophy of science is the logical empiricists' division between discovery and justification, which continues to be an issue of debate. In questioning whether LE is dead, it is important to ask which philosophers and which of their theses should be considered LE. As a philosophical movement, namely as an "-ism," LE may indeed be dead; however, a number of the individual theses continue to influence philosophy and the logic of mathematics.

The answer to the question of whether LE is dead also depends on the perspective taken. Does the perspective consider how LE formulations help scientists? Or, is the perspective more aligned with that of school philosophy, in which new philosophical knowledge is appreciated in its own right, even though that knowledge may not be applicable to problems that scientists face today or will likely face in the future.

\subsection{Positivism Dispute}

In the $1960 \mathrm{~s}$, a positivism dispute occurred in which Jürgen Habermas (1977) accused Popper of being a positivist. The peculiarity of the dispute was that no member of the positivism dispute-including Popper - admitted to being a positivist (Frisby, 1977). Popper was a "critical rationalist," and he declared himself to be the killer of positivism (in Popper, 1934). Popper replied to Habermas that if Habermas's definition of positivism was accepted, then it would make Marx, Engels, and Lenin positivists (e.g., Popper, 1969, p. 300). The positivism dispute may explain why falsification, commonly associated with Popper, is mentioned in IS as part of LP (Evaristo \& Karahanna, 1997; Lee, 1991).

\section{The Use of Positivism in Information Systems}

Many IS articles note that the majority of IS studies are positivistic. For example, Mingers (2001, p. 240) reported that $97 \%$ of the articles analyzed by Orlikowski and Baroudi (1991) used "a positivist framework." Evaristo and Karahanna (1997) noted that LP dominates North American IS research. The high rates of positivistic research above can be explained by the fact that these studies (Evaristo \& Karahanna, 1997; Orlikowski \& Baroudi, 1991) classify, for example, survey research with independent variables as positivistic, irrespective of whether the authors declare themselves to be adherents of positivism. An alternative way of reviewing "positivism" in IS would be to examine those articles which utilize the terms "positivism" or "positivist," to analyze what the authors mean by these terms, and to understand which are the most influential sources of positivistic beliefs. This is what we describe next. 
Table 1. The Use of Positivism in Articles Published in the Basket of Six Journals (Number of Papers Referring to Positivism and Percentage of the Total Publications).

\begin{tabular}{|c|c|c|c|c|c|c|c|c|c|c|c|c|}
\hline & \multicolumn{2}{|c|}{ MISQ papers } & \multicolumn{2}{|c|}{ ISR papers } & \multicolumn{2}{|c|}{ EJIS papers } & \multicolumn{2}{|c|}{ ISJ papers } & \multicolumn{2}{|c|}{ JAIS papers } & \multicolumn{2}{|c|}{ JMIS papers } \\
\hline Year & $\begin{array}{c}\text { Number } \\
\text { of } \\
\text { papers }\end{array}$ & $\begin{array}{l}\text { Percent } \\
\text { of total } \\
\text { in year }\end{array}$ & \begin{tabular}{|c|} 
Number \\
of \\
papers
\end{tabular} & $\begin{array}{c}\text { Percent } \\
\text { of total } \\
\text { in year }\end{array}$ & $\begin{array}{c}\text { Number } \\
\text { of } \\
\text { papers }\end{array}$ & $\begin{array}{c}\text { Percent } \\
\text { of total } \\
\text { in year }\end{array}$ & \begin{tabular}{|c} 
Number \\
of \\
papers
\end{tabular} & $\begin{array}{c}\text { Percent } \\
\text { of total } \\
\text { in year }\end{array}$ & $\begin{array}{c}\text { Number } \\
\text { of } \\
\text { papers }\end{array}$ & $\begin{array}{c}\text { Percent } \\
\text { of total } \\
\text { in year }\end{array}$ & \begin{tabular}{|c|} 
Number \\
of \\
papers
\end{tabular} & $\begin{array}{c}\text { Percent } \\
\text { of total } \\
\text { in year }\end{array}$ \\
\hline 2015 & 4 & $9.30 \%$ & 1 & $2.17 \%$ & 4 & $10.53 \%$ & 3 & $11.54 \%$ & 2 & $7.14 \%$ & 0 & $0.00 \%$ \\
\hline 2014 & 2 & $3.77 \%$ & 2 & $3.92 \%$ & 9 & $20.93 \%$ & 1 & $4.55 \%$ & 5 & $13.89 \%$ & 0 & $0.00 \%$ \\
\hline 2013 & 13 & $18.84 \%$ & 1 & $1.59 \%$ & 11 & $26.19 \%$ & 1 & $4.35 \%$ & 3 & \begin{tabular}{|l|}
$10.71 \%$ \\
\end{tabular} & 0 & $0.00 \%$ \\
\hline 2012 & 6 & $8.57 \%$ & 2 & $3.39 \%$ & 10 & $28.57 \%$ & 5 & $23.81 \%$ & 4 & $11.43 \%$ & 0 & $0.00 \%$ \\
\hline 2011 & 4 & $7.27 \%$ & 3 & $5.88 \%$ & 9 & $18.75 \%$ & 5 & $23.81 \%$ & 3 & $8.57 \%$ & 2 & $5.26 \%$ \\
\hline 2010 & 8 & $18.60 \%$ & 2 & $3.57 \%$ & 6 & $16.22 \%$ & 4 & $19.05 \%$ & 1 & $3.13 \%$ & 1 & $2.50 \%$ \\
\hline 2009 & 7 & $14.58 \%$ & 2 & $6.25 \%$ & 3 & $7.14 \%$ & 1 & $4.35 \%$ & 1 & $3.33 \%$ & 0 & $0.00 \%$ \\
\hline 2008 & 5 & $12.50 \%$ & 1 & $3.45 \%$ & 12 & $27.91 \%$ & 4 & $22.22 \%$ & 4 & $12.50 \%$ & 2 & $4.88 \%$ \\
\hline 2007 & 4 & $10.81 \%$ & 1 & $3.70 \%$ & 8 & $14.29 \%$ & 7 & $35.00 \%$ & 3 & $9.09 \%$ & 0 & $0.00 \%$ \\
\hline 2006 & 4 & $8.51 \%$ & 0 & $0.00 \%$ & 9 & $8.51 \%$ & 2 & $14.00 \%$ & 2 & $5.71 \%$ & 2 & $5.00 \%$ \\
\hline 2005 & 2 & $5.71 \%$ & 0 & $0.00 \%$ & 1 & $3.45 \%$ & 3 & $17.00 \%$ & 2 & $14.29 \%$ & 2 & $5.00 \%$ \\
\hline 2004 & 8 & $27.59 \%$ & 1 & $4.17 \%$ & 3 & $13.64 \%$ & 5 & $29.41 \%$ & 2 & $11.11 \%$ & 1 & $2.86 \%$ \\
\hline 2003 & 3 & $11.11 \%$ & 1 & $5.88 \%$ & 4 & $19.05 \%$ & 2 & $11.76 \%$ & 4 & $26.67 \%$ & 0 & $0.00 \%$ \\
\hline 2002 & 3 & $9.68 \%$ & 5 & $17.24 \%$ & 1 & $4.76 \%$ & 1 & $6.25 \%$ & 2 & $28.57 \%$ & 1 & $2.78 \%$ \\
\hline Total & 73 & $11.65 \%$ & 22 & $4.17 \%$ & 90 & $17.24 \%$ & 44 & $15.88 \%$ & 38 & $9.52 \%$ & 11 & $2.01 \%$ \\
\hline
\end{tabular}

\subsection{The Use of the Concept of Positivism in Top IS Journals}

We reviewed the Association for Information Systems Basket of Six journals-MIS Quarterly (MISQ), Information Systems Research (ISR), European Journal of Information Systems (EJIS), Information Systems Journal (ISR), Journal of the Association for Information Systems (JAIS), and Journal of Management Information Systems (JMIS) - for the period of 2002-2015 to determine whether they used the term "positivism" or "positivist"; if they did, we analyzed what was implied by these concepts. For example, in $2013,18.8 \%$ of all of the articles published in MISQ and $26.2 \%$ of all of the articles published in EJIS referred to positivism (Table 1). The analysis shows that 73 papers in MISQ, 90 papers in EJIS, 44 papers in ISJ, and 38 papers in JAIS referred to the concept during the 13 years. An interesting observation is that, in 2004, Weber, in his MISQ editorial, asked that authors stop viewing IS research through positivism and interpretivism (Weber, 2004). His request, however, has not stopped MISQ authors' utilization of the term "positivism." Next, we describe the key sources of positivistic beliefs in IS, based on the citations that were used by the 278 articles in defining positivism.

\subsection{Where Did the IS Ideas of Positivism Originate?}

From a total of 278 IS papers (found in MISQ, ISR, EJIS, ISJ, JAIS, and JMIS) for the period of 20022015, $126(45.3 \%)$ utilized the concept by claiming that they adopted it or positioned themselves against it. However, they did not explain what they meant by the concept nor did they provide any references related to positivism. Our analysis indicated that only one paper (out of 278) cited any philosopher who, based on our understanding, viewed himself as a positivist. Porra, Hirschheim, and Parks (2014) mention Comte, who first introduced the term "positivism." So, the question then becomes from where do the positivistic beliefs in IS stem if the IS articles that we analyzed did not cite or name positivistic philosophers? For those papers that cited an article as the source of positivism (as mentioned, $45 \%$ did not cite anyone), Orlikowski and Baroudi's (1991) paper was the most influential (23\% of the analyzed IS papers used it to describe what positivism means), Klein and Myers's (1999) study was the second most influential (used by $12.5 \%$ of the papers), followed by Walsham (1995) 10\%, Lee (1991) 9\%, Dubé and Paré (2003) 8.5\%, and Eisenhardt (1989) $6.5 \%$. Table 2 illustrates on which sources these papers, in turn, base their views on LP or positivism. 
Table 2. The Most Influential Papers on IS Positivism and their Sources for Positivism.

\begin{tabular}{|l|l|}
\hline $\begin{array}{c}\text { Most influential papers on IS } \\
\text { positivism }\end{array}$ & \multicolumn{1}{c|}{ Reference papers that are cited for defining positivism } \\
\hline Orlikowski \& Baroudi (1991) & $\begin{array}{l}\text { Chua (1986), Evered \& Louis (1981), Galliers \& Land (1987), Morgan (1980), Morgan \& } \\
\text { Smircich (1980) }\end{array}$ \\
\hline Klein \& Myers (1999) & Lee (1989), Yin, (1994), Orlikowski \& Baroudi (1991) \\
\hline Walsham (1995) & Orlikowski \& Baroudi (1991) \\
\hline Lee (1991) & Hempel (1969), Kolakowski (1968), Popper (1968) \\
\hline Dubé \& Paré (2003) & Orlikowski \& Baroudi (1991), Devers (1999), Lincoln \& Guba (1985), Lee (1989) \\
\hline Eisenhardt (1989) & No reference for defining positivism \\
\hline
\end{tabular}

The most influential source is Orlikowski and Baroudi (1991), who mainly refer to Chua (1986) as their source for positivism. ${ }^{16}$ Chua (1986) associates positivism with the verification method (in comparison with the falsification method advocated by Popper). The verification method mentioned by Chua (1986) is a positivistic thesis, especially in Schlick's view of LP (Schlick, 1932).

The second most influential source is Klein and Myers (1999), who mainly refer to Orlikowski and Baroudi (1991), but also to Lee (1989). Lee (1989) has been cited as "positivistic" in IS literature. Nonetheless, although Lee (1989 p. 34) utilizes the "natural science model of social science," logical positivism is only mentioned in one footnote.

The third most influential source is Walsham (1995), who views positivism as a belief in objective data, and also as the opposite of interpretative research (p. 376). Walsham cites Orlikowski and Baroudi (1991) as a source when associating positivism with "formal propositions, quantifiable measures of variables, the use of hypothesis testing, and drawing of inferences about phenomena from a sample to a stated population" (Walsham, 1995, p. 383).

The fourth most influential source is Lee's (1991) article. Lee $(1991$, p. 343) correctly points out that within LP there was a theme called "the unity of sciences." In addition, Lee (1991) outlines a number of ideas, which he claims to be positivistic, e.g., "inferential statistics" and "four requirements of falsifiability" (i.e., relative explanatory power,

${ }^{16}$ A number of sources for positivism — such as Galliers and Land (1987), Morgan and Smircich (1980), and Morgan (1980) — make no use of the term "positivism." Morgan (1980) discusses "functionalism," but not positivism. Functionalism means objective and value-free social science, with the scientist distanced from the scene that he or she hypothetico-deductive logic, the rules of formal logic, and survival) (Lee, 1991, p. 343-343, 347).

Eisenhardt (1989, p. 546), who also influenced IS research in the use of positivism, defines positivism as "toward the development of testable hypotheses and theory which are generalizable across settings."

IS studies (in our sample) primarily used these sources when referring to the meaning of positivism. The analysis further suggests that many of the influential views on positivism in IS (e.g., Klein \& Myers, 1999; Dubé \& Paré, 2003; Walsham, 1995) are based on the first source, Orlikowski and Baroudi (1991). Next, we describe the main beliefs that IS researchers associate with positivism, as determined through our analysis of their articles.

\subsection{How the Most Influential Papers on Positivism in IS Define Positivism}

We have identified the articles that have been most influential in terms of how positivism is defined by IS researchers. Next, we briefly describe how most of these influential papers on IS positivism "define" (or characterize) the term positivism, so that we can retrace how IS researchers understand positivism. Based on our review (see Table 1), the assumptions presented in Table 3 are repeated by IS scholars when they utilize positivistic research methods or when they state that their underlying assumptions are based on positivism or against it.

analyzes through the rigor and technique of the scientific method (Morgan, 1980). Morgan and Smircich (1980) do not mention positivism, but rather refer to objectivism. Objectivistic research believes in an exterior world that is an objective phenomenon that lends itself to direct observation and measurement (Morgan \& Smircich, 1980). 
Table 3. Assumptions Justified under the Philosophy of Positivism in IS Research.

\begin{tabular}{|c|c|}
\hline Assumptions & References \\
\hline A priori fixed relationships within phenomena & $\begin{array}{l}\text { Orlikowski \& Baroudi (1991), Klein \& Myers } \\
(1999)^{*} \text {, Dubé \& Paré (2003)* }\end{array}$ \\
\hline $\begin{array}{l}\text { Formal propositions, quantifiable measures of variables, hypotheses and theory } \\
\text { testing, and large-scale sample surveys and controlled laboratory experiments }\end{array}$ & $\begin{array}{l}\text { Orlikowski \& Baroudi (1991), Klein \& Myers } \\
(1999), \text { Walsham (1995)* }\end{array}$ \\
\hline Independent and dependent variables & Dubé \& Paré (2003) \\
\hline Testing prior theories or hypotheses using "objective" data & Walsham (1995) \\
\hline Testable hypotheses and theories that are generalizable across settings & Eisenhardt (1989), Dubé \& Paré (2003) \\
\hline $\begin{array}{l}\text { Inferential statistics, hypothesis testing, mathematical analysis, and } \\
\text { experimental and quasi-experimental } \\
\text { design }\end{array}$ & Lee (1991) \\
\hline $\begin{array}{l}\text { Testing theoretical propositions against the rules } \\
\text { of formal logic and hypothetico-deductive logic, and satisfying falsifiability, } \\
\text { logical consistency, relative explanatory power, and survival }\end{array}$ & Lee $(1991)$ \\
\hline The objective physical and social world that exists independently of humans & $\begin{array}{l}\text { Orlikowski \& Baroudi (1991), Dubé \& Paré } \\
(2003)^{*}\end{array}$ \\
\hline Precise scientific concepts with fixed and invariant meanings & Orlikowski \& Baroudi (1991) \\
\hline A passive, neutral, and value-free researcher & $\begin{array}{l}\text { Orlikowski \& Baroudi (1991), Klein \& Myers } \\
\text { (1999), Dubé \& Paré (2003), Walsham (1995) }\end{array}$ \\
\hline Social sciences should emulate the natural sciences & $\begin{array}{l}\text { Orlikowski \& Baroudi (1991), Dubé \& Paré } \\
\text { (2003), Lee (1991) }\end{array}$ \\
\hline Validity and reliability issues as used in the natural sciences & Dubé \& Paré (2003) \\
\hline
\end{tabular}

Next, we explain the assumptions concerning positivism.

\section{Discussion of the Assumption Concerning "Positivism"}

Of the assumptions presented in Table 3 , we argue, with certain reservations, that the only one that was quite correctly associated with the LP philosophy was "objective data" by Walsham (1995). ${ }^{17}$.Moreover, we accept the possibility that a priori fixed relationships within phenomena can be regarded as "positivistic" through specific laws (see Section 4.5). Next, we briefly summarize why the other assumptions (in Table 3) are not in line with LP.

\subsection{Is Survey Research Positivistic?}

Logical positivists did not advocate survey research, nor was it their preferred method. Nevertheless, two issues are relevant in considering whether survey research can be regarded as positivistic. First, it is debatable whether a survey would qualify as

\footnotetext{
${ }^{17}$ Rather than objective data, it would be perhaps better to say that there is an objective basis for observations. Nevertheless, Neurath might not have accepted this.

18 Imagine that we test different systems/programs with different characteristics, and we define a system's ease of use through these characteristics. Then, we could test whether
}

verification by observation in LP terms. However, the more important issue that we discuss is that, if a survey were to count as a verification by observation, then the survey questions should refer to concretely identifiable characteristics (in order to be positivistic). For example, we assert that constructs measuring the "ease of use" by statements (e.g., "I find the system easy to use") would be meaningless for LP philosophers, as they do not specify the precise system or software features. ${ }^{18} \mathrm{We}$ view survey studies that specify concrete system characteristics (in connection to ease of use) as "more positivistic," than those that do not precisely specify the system features..$^{19}$ Nevertheless, it is questionable whether any form of survey research that uses probabilities is "scientific" in light of LP. This is what we discuss next.

\subsection{Statistical Methods are not Especially Positivistic Methods}

Many of the IS beliefs about positivism relate to (probabilistic) statistical techniques and studies.

these characteristics of ease of use are key in explaining the use of a system or application.

19 As mentioned, if we apply the strict requirement of absolute verification or analytic/synthetic, then perhaps no study is positivistic. 
Statistical data analysis alone does not mean that the study is scientific from the perspective of LP. LP's term analytical should not be confused with statistical research, if the particular statistical research ultimately concerns the examination of an empirical phenomenon. Moreover, it seems that probabilistic statements were not acceptable for logical positivists (von Wright, 1945). LP's ambition was much higher, claiming that there should be conclusive evidence or a finite set of data that could be examined, in order to verify a statement (Hempel, 1950). ${ }^{20}$

\subsection{Are Qualitative Studies Positivistic?}

From the previous discussion, it is clear that whether or not qualitative studies are positivistic is unrelated to sample size or the utilization of statistics to analyze qualitative data. What then was the status of qualitative studies in LP? We argue that if we have to select a research method used in IS and favored by LP philosophers, then a strong candidate would be qualitative observation. Logical positivists (e.g., Schlick, 1932) provided a number of examples of how animals and planets are examined by direct observation using the naked eye or a telescope. Carnap and Neurath even outlined different protocols to record observations. Briefly, Carnap (1932b) viewed the protocol as short, "now it is raining hard." Neurath asserted that the protocol sentence must be more exact, in that it must include references to time, the name of the observer, and the exact conditions. Neurath's version of a protocol sentence was, "Otto Neurath witnesses rain in Viennastrasse 4 at 3 o'clock, 11/11/1932" (Neurath, 1932; Nottelmann, 2006). We regard Neurath's protocol sentence as an example of qualitative field notes.

\subsection{Independent and Dependent Variables were not Especially Important for LP}

Based on our reading, LP philosophers did not require scientific statements to have independent (IV) or dependent (DV) variables. LP required empirical claims to have identifiable (observable) characteristics. For example, "this table is red" is an acceptable claim for LP, as long as we know to which table we are referring (and we know that red refers to color). This example (and

\footnotetext{
${ }^{20}$ We suggest the following interpretation. Consider, "this table is red" versus "there is a $60 \%$ chance that this table is red." The former claim is not probabilistic, while the latter is probabilistic. We believe that the reason that LP did not allow probabilities was that, by allowing probability, one could not have an absolute criterion that ultimately separates metaphysical claims as meaningless.

${ }^{21}$ For example, "Traditionally, the word 'laws' has been reserved for universally applicable, exceptionless generalizations" (Teller, 2004, p. 731).
}

Neurath's example of field notes above) also illustrates that LP philosophers accepted what IS scholars might refer to as descriptive (atheoretical) research.

\subsection{Fixed Relationships or Change?}

There are various ways to approach this issue. One way is to associate fixed relationships with scientific laws. The standard account of laws (around 1920-1930, ca. up to 1970 s) was that laws are strictly unrestricted universal statements, and hence deterministic. ${ }^{21}$ Such laws seem to assume fixed relationships. In IS, positivist researchers reportedly use experiments and surveys with inferential statistics to "discover causal laws" or "universal laws" (Orlikowski \& Baroudi, 1991, p. 10). However, it is not clear how surveys using statistical (probabilistic) techniques can discover universal (100\% exceptionless) laws. The other possible interpretation would be to claim that LP was not a movement that was for or against fixed phenomena. LP members highlighted the need to examine issues empirically and not look toward philosophy in deciding such matters a priori. ${ }^{22}$ Either stability or change can be acceptable for LP if it satisfies the verification principle.

Finally, Neurath $(1931,1944)$ stresses dynamism and unpredictability. Neurath asserts that: (1) phenomena are highly complex; (2) we often lack the specific details to predict a singular act (e.g., at what exact time an earthquake will occur and what the precise impact will be); and (3) even a single act — which we often cannot predict - can cause enormous consequent events that are even more difficult to predict. For Neurath, prediction is theoretically possible in science (Reisch, 2001), but is impossible in practice (Reisch, 2001).

\subsection{Objective Data and LP}

Objective data, or rather an objective basis for observation, can be viewed as positivistic, especially according to Schlick's positivism. Schlick's verification thesis involved an observation that indicates whether an empirical statement is true or untrue with absolute certainty. According to this idea, a biochemistry scholar makes an observation through a microscope and draws a conclusion with absolute certainty. If there is absolute objectivity in the observations, then Schlick's verification (1936) could

\footnotetext{
${ }^{22}$ Following this interpretation, a belief that relationships are a priori fixed would be a metaphysical claim for LP, which should be avoided. Neurath (1931) agrees that one should look to science to see how things are, and not engage in "philosophizing." Hahn, a LP member, (1930/1980, p. 20) maintains that the role of philosophy is only to see that scientific propositions "are not pseudo-propositions" (Hahn, 1930/1980, p. 20).
} 
work as an absolute method. However, problems in establishing an objective basis for observation were a key reason that logical positivists destroyed their own movement. Demolishing the objective basis for observation is commonly attributed to the critics of LP - e.g., Hanson's (1958) "theory ladenness of observation," Quine's (1951) underdetermination, and a number of theses by Feyerabend (1975) and Kuhn (1962). However, many years before Feyerabend, Hanson, Kuhn, and Quine, Neurath argued against Schlick that our observations are not independent of speculation. Specifically, any observation is inspired by our background beliefs, e.g., our own education, beliefs, speculations, theories. When these background beliefs change, the expected observation results may change as well. ${ }^{23}$

\subsection{Generalizability across Different Settings and LP}

Lee and Baskerville (2003, p. 231) claimed that "the study of a single setting (e.g., the setting of the fox in their reservation in Iowa) is an interpretive researcher's objective," but not a positivist's objective, which is "generalizable across different settings." 24 We find this interpretation problematic. Logical positivists (e.g., Schlick, 1932) would have allowed the study of a "single setting (e.g., the setting of a fox in their reservation in Iowa)" (Lee \& Baskerville, 2003, p. 231). For example, Schlick (1932) provides examples of observational studies of (1) animals that only live in Africa, and (2) certain features of specified planets. ${ }^{25}$ Also, Neurath's protocol sentences (Section 4.3) allowed for the study of a single setting.

\footnotetext{
${ }^{23}$ A concrete example would be primary brain lymphoma (a type of cancer). Under a microscope, the growth pattern (angiotropism) of primary brain lymphoma resembles sarcoma (a different type of cancer), and primary brain lymphoma was confused with sarcoma long before more specific ways to recognize it through a microscope were identified (Bhagavathi \& Wilson, 2008). A scholar who has a "theoretical" understanding of the sarcoma, but does not have a knowledge of what primary brain lymphoma looks like under a microscope, may not be able to discern the difference between primary brain lymphoma and sarcoma.

24 One way to defend "generalizable across different settings" (Lee \& Baskerville, 2003, p. 231) as positivistic is to suggest that logical positivists advocated laws, and laws require generalizability. One problem with this approach is the following: The standard account of laws is that laws are $100 \%$ exceptionless generalizations (Teller, 2004). It is questionable if IS research can have such generalizations.

${ }^{25}$ Schlick (1932, p. 484): "There is not the least doubt that the proposition 'there is a 3000 meter mountain on the other side of the moon' makes good sense, even though we lack the technical means of verifying it. And it would remain just as meaningful if one knew with certainty, on scientific grounds, that no man would ever reach the other side of the
}

\subsection{Ontological Questions were Nonsense for Logical Positivists}

Claims, e.g., "an objective physical and social world that exists independent of humans" (Orlikowski \& Baroudi, 1991, p. 8), are ontological (about reality and existence). It is rather difficult to conduct such ontological discussions with the principles of LPe.g., "Is this a logical problem? If so, can you prove it logically/mathematically?" (analytical), or "Is this an empirical problem?" (synthetic). Anything that fails to satisfy these criteria is meaningless. It is therefore not surprising that logical positivists regarded any discussion of the existence of the physical world (roughly speaking ontological discussions) as "meaningless pseudo-problems" (Schlick, 1932). More specifically, Schlick's point was not to make a claim about whether there is a reality; rather, his claim was that the entire discussion of this matter is meaningless. ${ }^{26}$ Carnap (1963b, p. 868) declared that, for the Vienna positivists, "The statement asserting the reality of the external world (realism) as well as its negation in various forms . . . are pseudo-statements" by definition.

\subsection{Precise Concepts and LP}

The IS belief that LP valued precise concepts is partly correct. LP valued precision in terms of requiring that metaphysics must be removed from scientific sentences and that all terms in empirical sentences must have observable characteristics. The claim that LP concerns precise concepts is partly correct in the sense that having identifiable terms requires that concepts are precisely defined or well known. However, precise concepts are not automatically

moon." Roughly speaking, here Schlick provide an example of a "scientific" proposition, which is tantamount to meaningful in the terminology of LP. For Schlick's (1932) LP, all theories were broken down to individual propositions, which were verified individually. For LP, theory could be just one proposition. For Schlick's LP, synthetic (empirical) propositions that did not contain verifiable terms were regarded as meaningless (nonsense) and not scientific. Schlick's example of an acceptable scientific proposition is "there is a 3000 meter mountain on the other side of the moon" (p. 484). As can be seen, this mountain proposition does not refer to mountains in general, it refers to one specific mountain, and the specific or unique characteristics of that mountain (3000 meters). In his example, Schlick does not require that this observation has to be generalized to other mountains. This example implies that Schlick, the founder of LP, regarded the examination of unique aspects as scientifically acceptable.

26 Schlick's position on realism is complex. One interpretation is that Schlick is a realist (cf. "only the given is real"; Schlick, 1932), but he nevertheless regarded the discussion on realism (and issues thereof) as a meaningless pseudoproblem, which should be avoided. There are other possible interpretations, but they cannot be discussed here. 
scientific (meaningful) for LP-i.e., one could have precise definitions that are meaningless.

\subsection{Logical Positivists were not Passive, Neutral, or Value-Free Thinkers}

It is understandable that the IS literature regards LP as a neutral, passive, and value-free approach to science. The idea of LP seems to approach neutrality: Can you prove your proposition mathematically or assert a scientific statement that can be verified? While this activity may appear value-free, $L P$ itself was not valuefree. LP suggested regarding metaphysics as meaningless, for example, which was far from being a value-free aim (Laudan, 1983). Carnap admitted that in attempting to discard metaphysics, he was targeting the philosophy of Martin Heidegger (Diesing, 1991), thus constituting a value-laden objective. In addition, the Vienna Circle positivists were not themselves passive observers. Carnap (1963a, p. 32) claimed that the members of the Vienna Circle were socialists and advocated scientific humanism.

Neurath noted that all sciences are based on a number of values and that value-free science is not necessary (Cat, 2014), adding that in the social and natural sciences, scholars are not passive observers. His examples were self-fulfilling prophecies. The point was that human beings are intentional, and they change their behavior; moreover, scientists' interventions or results can also change humans' behavior. ${ }^{27}$

\subsection{The Claim that Social Sciences Should Emulate the Natural Sciences}

Another fundamental belief that pertains to the meaning of positivism for some IS scholars is that the social sciences should emulate the natural sciences, for example, methodologically (e.g., Ngwenyama \& Lee, 1997; Lee, 1991; Lee \& Hubona, 2009).

We propose the following interpretation. For LP, the key was not the unity of the specific research methods that the scholars utilized (unless verification, protocol sentences, or observation are regarded as the method). The concern was, once again, with metaphysics. ${ }^{28} \mathrm{It}$ was believed that different sciences may contain conflicting concepts, some of which could turn out to

\footnotetext{
${ }^{27}$ E.g., a scientist who predicts that a meteorite will fall at a specific place at a certain time, thereby resulting in the death of numerous people (Reisch, 2001). Since merely stating the prediction may lead to people fleeing the area (Reisch, 2001), a scholar's statements can influence human action.

${ }^{28}$ The LP "unity of science" discussion also related to the manner in which different scientific domains connect with each other to form a framework of united science. Carnap and Neurath advocated opposite views. Carnap proposed a hierarchical structure of sciences, with physics being the fundamental science and located at the base of the hierarchy. Neurath did not accept the primacy of physics and suggested an encyclopedia-like model in which the different sciences
}

be metaphysical (von Wright, 1945). Such metaphysics could be avoided if all sciences were translated into a common "metaphysics-free" neutral language (von Wright, 1945; Tamminga, 2005). Logical positivists, however, disagreed on the details. ${ }^{29}$

\section{Implications}

The extent to which LP is useful for IS without careful and justified modifications is questionable. Nevertheless, provided that positivism is used to justify certain research orientations in IS, we first highlight two general implications for IS regarding positivism:

First, generally speaking, what has been justified as scientific by positivism in IS either was not required by logical positivists, or was regarded as nonsense by logical positivists. Influential IS articles on positivism present positivism as requiring statistical techniques, statistical generalizability, generalizability across different settings (as opposed to "single-setting" studies), independent and dependent variables, and the outlining of ontological stances. We argue that these were not required by logical positivists, or they were regarded as nonsense by logical positivists.

Second, many research orientations that are deemed "unscientific" in IS by the authority of positivism are, in fact, "scientific," in principle, according to $L P^{30}$. In IS, positivism is used to deem certain practices "unscientific"-e.g., "positivism requires the social sciences to incorporate these elements [independent and dependent variables, quantitative data, inferential statistics, experimental] if they are to become as scientific as natural sciences" (Lee \& Hubona, 2009, p. 237). The problem is that no such things were explicitly required by the positivist philosophers for the research to be scientific.

If the role of the model for science is LP, then things like "the positivist conception of generalizability, which pertains to generalizing a theory across different settings" (Lee \& Baskerville, 2003, p. 231), may not be required. Moreover, if positivism is "the model for the social sciences to live up to" (Lee \& Hubona, 2009, p. 238), then the single-setting observation study would seem to be acceptable in principle, and the

were not supposed to be reduced to the laws of physics, as the pyramid model suggested (Neurath, 1937; Uebel, 2010). ${ }^{29}$ Neurath (1932) worried that such a neutral universal language would itself be metaphysical. He also believed that no neutral language exists; all views are always imperfect because they are biased by our preconceptions. Carnap (1937) later rejected the idea of one language; he felt that there could be multiple different languages for each science. He also noted that the selection of the language was a totally subjective choice.

${ }^{30}$ Obviously, if we apply the strict requirement of absolute verification or analytic/synthetic, then perhaps no empirical study is truly positivistic. 
preferred method (if there is one) would seem to be qualitative observations recorded by field notes. In addition, if positivism is the role model for IS or social sciences, then no statistical methods would be required.

Moreover, our earlier analysis showed that the "successor" of LP - namely, LE-with which it is sometimes confused, is also a highly questionable foundation for many natural sciences, not to mention social sciences (Diesing, 1991). Anyone advocating LE ideas in IS research must demonstrate how the accumulated evidence against LE philosophers can be overcome. For example, those scholars proposing the use of the deductive-nomological model of explanation in IS (Hempel \& Oppenheim, 1948) should consider the critique of the model and how this critique applies to IS. ${ }^{31}$

Finally, our review of positivism in IS reveals a concern that extends beyond positivism. Specifically, by and large, the IS authors list their positivistic assumptions without an attempt to justify them. For example, articles may state certain assumptions as positivistic or declare that positivists required independent and dependent variables or quantitative studies. However, these articles do not explain why these assumptions are positivistic and why they are justified or important in science/IS, other than that they are assumed to be positivistic. Following something without understanding why it is important, and what the strengths and weaknesses of such a view are, can constitute dogmatism, and IS research should be cognizant of this hazard.

\section{Conclusion}

LP is employed to authorize a number of research assumptions as "scientific" and deem another set of orientations as "unscientific." However, the philosophy of positivism hardly provides a justification for many influential IS beliefs about positivism-including statistical or nonstatistical generalizability, surveys, independent and dependent variables, and declaring ontological views. As a result, many influential beliefs on IS positivism are debunked.

${ }^{31}$ For example, "The current debate in philosophy of science is not about whether we should replace Hempel's account [the covering law account of explanation, deductive-
In turn, many research orientations that IS positivism judges to be "unscientific" per LP (e.g., single-setting research, examination of change, qualitative research), would seem to be "scientific" according to LP. Furthermore, the use of positivism in IS calls for a further analysis of the fundamental beliefs of IS. An analysis of key concepts and beliefs is critical, as there is a risk that IS scholars may inappropriately utilize lofty philosophical concepts to determine what constitutes accepted, scientific, or high-quality research. When concepts are used in this way to demarcate or characterize what is considered to be good science, then they have the potential to not only direct research, but also to disregard important research that does not meet the assumed beliefs. For example, if we assume and teach our doctorate students that research must have static variables in order to be scientific, then we may omit change, may test our models one time only, or we may abstract our models from the phenomenon so much that the results finally look static in the end. But what happens if the IS phenomena are not static, but highly dynamic? In such circumstances, our assumptions that scientific research must focus on fixed static variables could seriously hinder the progress of IS research and decrease practical applicability. Realizing that certain influential, taken-for-granted assumptions underlying IS research are unwarranted, could have groundbreaking implications for future IS research.

\section{Acknowledgments}

We want to thank Senior Editor, Prof. Shirley Gregor for her comments on the structuring and writing of the paper. We thank Tuula Klaavuniemi, MD, PhD for providing the sarcoma and primary brain lymphoma example, and explaining how (microscope) observations in biology, biochemistry, and medical research can be influenced by background beliefs. We also thank the anonymous reviewers for their numerous comments on the paper. Prof. Emeritus Pertti Järvinen, Prof. Andrew Burton-Jones, Prof. Suzanne Rivard, Prof. Tuure Tuunanen, and Dr. Mari Karjalainen are also acknowledged for their comments on early versions of this paper.

nomological model], but what should be the replacement" (Ylikoski, 2013, p. 384). 


\section{References}

Bhagavathi, S., \& Wilson, J. (2008). Primary Central Nervous System Lymphoma. Archives of Pathology \& Laboratory Medicine, 132(11), 1830-1834.

Bechtel, W., \& Abrahamsen, A. (2005). Explanation: a mechanist alternative. Studies in History and Philosophy of Biological and Biomedical Sciences, 36(2), 421-441.

Bourdeau, M. (2013), August Comte. In E. N. Zalta (Ed.), Stanford encyclopedia of philosophy (Winter 2013 ed.). Retrieved from http://stanford.library.usyd.edu.au/archives/wi n2013/entries/comte/index.html

Burian, R. (1977). More than a marriage of convenience: On the inextricability of history and philosophy of science. Philosophy of Science, 44(1), 1-42.

Carnap, R. (1932a). Überwindung der Metaphysik durch logische Analyse der Sprache. In R. Carnap (Ed.), Erkenntnis (Vol. 2, pp. 219-241). Leipzig, Germany.

Carnap, R. (1932b). Über Protokollsetze, Erkenntnis. In Carnap (Ed.), Erkenntnis (Vol. 2: 2-3, pp. 215-228). Leipzig, Germany.

Carnap, R. (1937). Testability and meaning, Philosophy of Science, 3(4), pp. 419-471.

Carnap, R. (1950). Logical foundations of probability. Chicago, IL: University of Chicago Press.

Carnap, R. (1963a). Rudolf Carnap: Intellectual autobiography. In P. A. Schilpp (Ed.), The philosoply of Rudolf Carnap (pp. 1-81). Chicago, IL: Open Court

Carnap, R. (1963b). My Views On Ontological Problems of Existence. In P. A. Schilpp (Ed): The philosoply of Rudolf Carnap (pp. 868-874). Chicago, IL: Open Court

Cartwright, N. (1983). How the laws of physics lie. Oxford, UK: Clarendon.

Cat, J. (2014). Otto Neurath. In E. N. Zalta (Ed.), Stanford encyclopedia of philosophy (Fall 2014 ed.). $\quad$ Retrieved from https://plato.stanford.edu/archives/fall2014/ent ries/neurath/

Chua W. F. (1986). Radical development in accounting thought. The Accounting Review, 61(4), 601632.

Creath, R. (2017). Logical Empiricism. In Edward N. Zalta (Ed.), The Stanford Encyclopedia of Philosophy (Fall 2017 ed.). Retrieved from https://plato.stanford.edu/archives/fall2017/ent ries/logical-empiricism/.

Devers, K. J. (1999). How will we know "good" qualitative research when we see it? Beginning the Dialogue in Health Services Research, Heath Services Research, 34(5), 1153-1188.

Diesing, P. (1991). How does social science work?: Reflections on practice. Pittsburg, PA: University of Pittsburg Press.

Dubé, L., \& Paré, G. (2003). Rigor in information systems positivist case research: Current practices, trends, and recommendations. MIS Quarterly, 27(4), 597-636.

Eisenhardt, K. (1989). building theories from case study research, The Academy of Management Review, 14(4), 532-550.

Evaristo J. R., \& Karahanna E. (1997) Is North American IS research different from European IS research. Data Base for Advances in Information Systems, 28(3), 32-43.

Evered, R., \& Louis, M. R. (1981). alternative perspectives in the organizational sciences: inquiry from the inside and inquiry from the outside. Academic Management Review, 6(3). 385-395.

Feigl, H. (1963). The power of positivistic thinking. Proceedings and Address of the American Philosophical Association, 36, 21-41.

Feigl, H. (1970). Beyond peaceful coexistence: Historical and philosophical perspectives of science. Minnesota Studies in the Philosophy of Science, 5, 3-11.

Fetzer, J. (2014). Carl Hempel. In E. N. Zalta (Ed.), Stanford encyclopedia of philosophy (Fall 2014 ed.). $\quad$ Retrieved from http://plato.stanford.edu/archives/fall2014/entr ies/hempel/

Feyerabend, P. (1975). Against method: Outline of an anarchist theory of knowledge. London: New Left Books.

Frisby, D. (1977) Introduction to the English translation. In T. Adorno, et al. (Eds.), The positivist dispute in German sociology (G. Adey \& D. Frisby, Trans.; pp. ix-xliv). London: Heinemann.

Galliers, R. D., \& Land, F. F. (1987). Choosing an appropriate information systems research methodology. Communications of the ACM, 30(11), 900-902.

Giere, R. N. (1973). The history and philosophy of science: Intimate relationship or marriage of 
convenience? The British Journal for the Philosophy of Science, 24(3), 282-297.

Giere, R.N. (1988). Explaining Science: A cognitive approach. Chicago, IL: The University of Chicago Press.

Godfrey-Smith, P. (1993) Functions: Consensus without unity. Pacific Philosophical Quarterly, 74(3), 196-208.

Godfrey-Smith, P. (1994) A modern history theory of functions. Nous, 2(3), 344-362.

Habermas, J. (1997). The analytic theory of science and dialectics. In T. Adorno, et al. (Eds.), The positivist dispute in German sociology (G. Adey \& D. Frisby, Trans.; pp. 131-162). London: Heinemann.

Hahn, H. (1930/1980). The significance of the scientific world view, especially for mathematics and physics (English trans., pp. 20-30). In B. McGuinness, (Ed.), Empiricism, Logic and Mathematics. Dordrecht, Germany: Springer.

Hanfling, O. (1996). Logical positivism. In G. H. R. Parkinson \& S. G. Shanker (Eds.), Routledge history of philosophy (pp. 193-213). London: Routledge.

Hanson, N. R. (1958). Patterns of discovery: An inquiry into the conceptual foundations of science. Cambridge, UK: Cambridge University Press.

Hedström, P., \& Ylikoski, P. (2010). Causal mechanisms in the social sciences. Annual Review of Sociology, 36(1), 49-67.

Hempel, C. G. (1935). On the logical positivists' theory of truth, Analysis, 2(4), 49-59.

Hempel, C. G. (1969). Logical positivism and the social sciences. In P. Achinstein \& S. Barker (Eds.), The legacy of logical positivism (pp. 163-194). Baltimore, MD: The Johns Hopkins University Press.

Hempel, C. G. (1950). Problems and changes in the empiricist criterion of meaning. Revue Internationale de Philosophie, 41(11), 41-63.

Hempel C. G., \& Oppenheim, P. (1948). Studies in the logic of explanation. Philosophy of Science, 15(2), 135-175.

Holton, J. G. (1993), Science and anti-science. Cambridge, MA: Harvard University Press.

Klein, H. K., \& Myers M. D. (1999). A set of principles for conducting and evaluating interpretive field studies in information systems. In special issue:
Intensive Research. MIS Quarterly, 23(1), 6793.

Kolakowski, L. (1968). The alienation of reason: A history of positivist thought, Garden City, NY: Doubleday.

Kuhn, T. (1962). Structure of scientific revolutions, Chicago, IL: University of Chicago Press.

Laudan, L. (1968). Theories of scientific method from Plato to Mach: A bibliographical review, History of Science, 7, 1-63.

Laudan, L. (1981). A confutation of convergent realism. Philosophy of Science, 48(1), 19-49.

Laudan, L. (1983). The demise of the demarcation problem. In R. S. Cohen \& L. Laudan, (Eds.), Physics, philosophy and psychoanalysis: Essays in honor of Adolf Grünbaum (pp. 111127). Dordrecht, Germany: D. Reidel.

Laudan, L., Donovan, A., Laudan, R., Barker, P., Brown, H., Leplin, J., Thagard, P., Wykstra, S. (1986). Testing theories of scientific change, Synthese, 69(2), 141-223.

Laudan, L. (1989). Thoughts on HPS: 20 years later. Studies in History and Philosophy of Science 20(1), 9-13.

Laudan, L. (1996). Beyond positivism and relativism: Theory, method, and evidence. Boulder, $\mathrm{CO}$ : Westview.

Lee, A. (1989). A scientific methodology for MIS case studies. MIS Quarterly, 13(1), 33-50.

Lee, A. (1991). Integrating positivist and interpretive approaches to organizational research. Organization Science, 2(4), 342-365.

Lee, A., \& Baskerville, R. L. (2003). Generalizing generalizability in information systems research. Information Systems Research, 14(3), 221-243.

Lee, A., \& Hubona G. S. (2009). A scientific basis for rigor in information systems research, MIS Quarterly 33(2), 237-262.

Lee, A., Briggs, R., \& Dennis, A. R. (2014). Crafting theory to satisfy the requirements of explanation. In Proceedings of 47th Hawaii International Conference on System Sciences, (pp. 4599-4608). AIS.

Lincoln, Y. S., \& Guba, E. G. (1985). Naturalist inquiry. Beverly Hills, CA: Sage.

Kaila, E. (1939). Inhimillinen tieto. Helsinki: Otava.

Machamer P., Darden L., \& Craver C. F. (2000). Thinking about mechanisms. Philosophy of Science, 67(1), 1-25. 
Manninen, J. (2002). Uuden filosifisen liikkeen ja sen manifestin synty. In I. Niiniluoto \& $\mathrm{H}$. Koskinen, (Eds.), Wienin Piiri (pp. 27-128). Helsinki: Gaudeamus.

McMullin, E. (1970). The history and philosophy of science: A taxonomy. In R. Steuwer, (Ed.), Minnesota Studies in the Philosophy of Science: Vol. 5. Historical and philosophical perspective of science (pp. 12-67). Minneapolis: University of Minnesota Press.

Milkov, N. (2013). The Berlin group and the Vienna Circle: Affinities and divergences. In N. Milkov $\&$ V. Peckhaus, (Eds.), The Berlin Group and the philosophy of logical empiricism (pp. 3-32). New York, NY Springer.

Mingers, J. (2001). Combining IS research methods: Towards a pluralist methodology. Information Systems Research, 12(3), 240-259.

Morgan, G. (1980). Paradigms, metaphors, and puzzle solving in organization theory. Administrative Science Quarterly, 25(4), pp. 605-622.

Morgan, G. \& Smircich, L. (1980). The case of qualitative research, Academy of Management Review, 5(4), 491-500.

Neurath, O. (1931), Physicalism: The philosophy of the Viennese Circle, The Monist, 41(4), 618623.

Neurath, O. (1932). Protocollsätze, Erkenntnis 3, pp. 204-214.

Neurath, O. (1937). Unified science and its encyclopaedia. Philosophy of Science, 4(2), 265-277.

Neurath, O. (1944). Foundations of the social sciences. In International encyclopedia of unified science (Vol. 2.1, pp. 1-51) (Chicago, IL: University of Chicago Press).

Nottelmann, N. (2006). Otto Neurath on the structure of protocol sentences: A new approach to an interpretative puzzle, Journal for General Philosophy of Science, 37(1), 165-186.

Ngwenyama, O., \& Lee, A. (1997). Communication richness in electronic mail: Critical social theory and the contextuality of meaning. MIS Quarterly, 21(2), 145-167.

Orlikowski, W. J., \& Baroudi, J. J. (1991). Studying information technology in organizations: Research approaches and assumptions, Information Systems Research, 2(1), 1-28.

Passmore, J. (1967). Logical positivism, In P. Edwards, (Ed.), The Encyclopedia of Philosophy (Vol. 5, pp. 52-57). New York, NY: Macmillan.
Popper K. (1934). Logik der Forschung. Tübingen, Germany: Mohr (Siebeck).

Popper, K. (1977). Reason or revolution. In T. Adorno, et al. (Eds.), The positivist dispute in German sociology (G. Adey \& D. Frisby, Trans.; pp. 288-300). London: Heinemann.

Popper K. R. (1968). The logic of scientific discovery. New York, NY: Harper Torchbooks.

Porra, J, Hirschheim, R., \& Parks, M. S. (2014). The historical research method and information systems research. Journal of the Association for Information Systems, 15(9), 536-576.

Quine, W. V. (1951). Two dogmas of empiricism. The Philosophical Review, 60(1), 20-43.

Reichenbach, H. (1936). Logistic empiricism in Germany and its present state of problems. Journal of Philosophy, 33(6), 141-160.

Reichenbach, H. (1938). Experience and prediction, Chicago, IL: University of Chicago Press.

Reichenbach, H. (1951). The rise of scientific philosophy. Berkeley: University of California Press.

Reisch, A. G. (2001). Against a third dogma of logical empiricism: Otto Neurath and "unpredictability in principle." International Studies in the Philosophy of Science, 15(2), 199-209.

Salmon, W. (2005). Scientific Realism in the empiricism tradition, In Reality and Rationality, (Dowe, P. and Salmon, M., Eds.), Oxford University Press, pp. 19-30

Schlick, M. (1932). Positivism and realism. English translation in Synthese (1948-1949), 7(1), 478505.

Siitonen, A. (2002). Looginen empirismi ja Hans Reichenbachin Experience and prediction. In I. Niiniluoto \& H. Koskinen, (Eds.), Wienin Piiri (pp. 149-167). Helsinki: Gaudeamus.

Stern, G. D. (2007). Wittgenstein, the Vienna Circle, and physicalism: A reassessment. In A. Richardson \& T. Uebel, (Eds.), The Cambridge companion to logical empiricism (pp. 305-331). Cambridge, UK: Cambridge University Press.

Tamminga, A. (2005). Introspection and change in Carnap's logical behaviourism. Studies in History and Philosophy of Science, 36(4), 650667.

Teller, P. (2004). The law-idealization. Philosophy of Science, 7(5), 730-741.

Uebel, T. (2007). Interpreting Neurath's protocols: Reply to Nottelmann. Journal for General Philosophy of Science, 38(2), 383-391. 
Uebel T. (2008). On the production of, history, and aspects of the reception of the Vienna Circle manifesto. Perspectives on Science, 16(1), 70102.

Uebel, T. (2010). Carnap and Neurath in exile: Can their disputes be resolved? International Studies in the Philosophy of Science, 15(2), 211-220.

Uebel, T. (2013). "logical positivism"—-"logical empiricism": What's in a name? Perspectives on Science, 21(1), pp. 58-99.

Uebel, T. (2014). Vienna Circle. In E. N. Zalta (Ed.), Stanford encyclopedia of philosophy (Spring 2014 ed.). Retrieved from http://plato.stanford.edu/archives/spr2014/entri es/vienna-circle

von Wright, G. H. (1945). Looginen empirismi-eräs nykyisen filosofian pääsuunta. Helsinki: Otava.

Walsham, G. (1995). The emergence of interpretivism in IS research. Information Systems Research, 6(4), 376-394.
Wayne, A. (2011). Expanding the scope of explanatory idealization. Philosophy of Science, 78(5), pp. 830-841.

Weber, R. (2004). The rhetoric of positivism versus interpretivism: A personal view. MIS Quarterly, 28(1), iii- xii.

Wittgenstein, L. (1921). Logisch-philosophische Abhandlung. Annalen der Naturphilosophische, 14(3/4).

Wittgenstein, L. (1922). Tractatus logicophilosophicus (English trans. of LogischPhilosophische Abhandlung, by C. K. Ogden). London: Routledge \& Kegan Paul. Retrieved from http://people.umass.edu/klement/tlp/tlp.pdf

Wittgenstein, L. (1958). Philosophical investigations (G. E. Anscombe, Trans.). New York, NY: Macmillan.

Ylikoski, P. (2013). The (hopefully) last stand of the covering-law theory: A reply to Opp. Social Science Information, 52(3), 383-393. 


\section{About the Authors}

Mikko Siponen is the vice dean for research and professor of information systems at the University of Jyväskylä. He has served for over ten years as the head of department, as well as the vice head and director of a research center. He holds a doctorate of social sciences in philosophy, M.Sc. in software engineering, Lic.Phil. in information systems, and $\mathrm{PhD}$ in information systems. He has received over $€ 10$ million in research funding from corporations and numerous other funding bodies.

Aggeliki Tsohou is a lecturer in the Department of Informatics at the Ionian University in Greece. She holds a B.Sc. in Informatics, a M.Sc. in Information Systems and a $\mathrm{PhD}$ in information security management. She worked as a postdoctoral researcher at the University of Jyväskylä, Finland, and as a senior research fellow at Brunel University.

Copyright $(92018$ by the Association for Information Systems. Permission to make digital or hard copies of all or part of this work for personal or classroom use is granted without fee provided that copies are not made or distributed for profit or commercial advantage and that copies bear this notice and full citation on the first page. Copyright for components of this work owned by others than the Association for Information Systems must be honored. Abstracting with credit is permitted. To copy otherwise, to republish, to post on servers, or to redistribute to lists requires prior specific permission and/or fee. Request permission to publish from: AIS Administrative Office, P.O. Box 2712 Atlanta, GA, 30301-2712 Attn: Reprints or via e-mail from publications@ aisnet.org. 